\title{
Studi Parameter Kecepatan Lalu Lintas Akibat Pengaruh Rumble Strips Terhadap Perilaku Pengemudi di Kampus Limau Manis Universitas Andalas
}

\author{
Putri Oktafiani Muchlis \\ Program Studi Teknik Sipil, Sekolah Tinggi Teknologi Dumai \\ Jl. Utama Karya Bukit Batrem II \\ Email: oktafia.pu3@gmail.com
}

\begin{abstract}
ABSTRAK
Kecelakaan lalu lintas sebagian besar disebabkan oleh pelanggaran terhadap peraturan keselamatan lalu lintas, hal ini menunjukan bahwa kesalahan manusia secara mandiri bertanggung jawab terhadap hampir 50\% kejadian. Penelitian ini bertujuan untuk mengetahui kecepatan kendaraan ketika melewati rumble strips yang ada di kampus Limau Manis UNAND. Penelitian dilakukan di lima lokasi rumble strips yang ada di kampus Limau Manis UNAND. Pengumpulan data di lapangan yaitu data kecepatan. Survei dilakukan di tanggal 14 Juni 2013- 4 juli 2013 pada hari kerja (jam 08.45 WIB sampai jam 17.30 WIB). Pengukuran dilakukan sebelum Rumble Strips, di rumble strips, dan ketika kendaraan akan meninggalkan Rumble Strips,saat meninggalkan rumble strips, Analisis untuk perbandingan pengujian penurunan kecepatan kendaraan ketika melewati rumble strips dengan menggunakan uji z dan $t$ serta uji chi square. Hasil analisis pengaruh rumble strips terhadap tingkat kecepatan kendaraan di Rumble Strips menunjukkan penurunan kecepatan, ketika melewati rumble strips dibandingkan sebelum atau sesudah rumble strips.
\end{abstract}

Kata kunci:kecepatan,rumble strips, uji z, uji t, uji chi square

\begin{abstract}
Traffic accident are mostly caused by violation of traffic safety rules. This indicates that human error is independently responsible for almost $50 \%$ of events. This study to determine the vehicle's speed when passing through the rumble strips in Limau Manis Campus UNAND. This study was conducted in fivelocation rumble strips that are on Limau Manis Campus UNAND. Field data collection is done velocity data. Survey conducted in date 14 juni 2013 - 4 juli 2013 and week day (08.45-17.30 WIB).Measurement were carried out before the rumble strips, in the rumble strips and when left the rumble strips. Comparative analysis for impairment testing vehicle speed when passing rumble strips using $z$ and $t$ test and chi square test. The result of analysis of the influence of rumble strips on the level of vehicle speed in rumble strips showed a decrease in speed when passing over the rumble strip before and after.
\end{abstract}

Keywords:Velocity, rumble strips, $z$ test, $t$ test, chi square test 


\section{Pendahuluan}

Pada berita terakhir yang dimuat Voice of America (Anonim, 2013) WHO melaporkan jumlah kematian tahunan akibat kecelakaan lalu lintas tetap tinggi dalam beberapa tahun terakhir. Menurut badan PBB itu, jumlah tersebut tidak akan turun, karena sedikit negara yang memiliki undang- undang keselamatan jalan yang menyeluruh yang bisa mencegah dan mengurangi korban jiwa maupun luka-luka. Tanpa tindakan untuk mengatasi masalah akibat perbuatan manusia ini, WHO memperkirakan sekitar 1,9 juta akan meninggal di jalan setiap tahun menjelang tahun 2020 .

Kecelakaan lalu lintas sebagian besar disebabkan oleh pelanggaran terhadap peraturan keselamatan lalu-lintas. Treat, dkk (dalam Widya Graha Asana, 2007) meneliti tentang hal ini dan mengemukakan bahwa faktor kesalahan manusia secara mandiri dan bertanggung jawab terhadap hampir 50\% kejadian. Melihat bahwa faktor kesalahan manusia merupakan penyumbang terbesar dalam kecelakaan, dibutuhkan adanya sistem keselamatan yang dapat mengendalikan perilakumanusia sebagai pengguna jalan, agar pelanggaran terhadap peraturan keselamatan lalu lintas berkurang jumlahnya. Selama ini pengendalian terhadap perilaku pengemudi kendaraan dilakukan dengan memberi sanksi legal kepada pelanggar. Efektifitas sanksi legal dibuat dan ditetapkan karena dipercaya merupakan alat yang dapat menuntun perilaku manusia kearah yang lebih diinginkan. Ada beberapa perangkat rekayasa lalu lintas yang bisa digunakan untuk merubah tingkah laku pengguna kendaraan sehingga pengendara tidak membahayakan kendaraan lain serta aman bagi lingkungan sekitarnya dan dapat mereduksi kecepatan kendaraan bermotor, salah satunya adalah dengan cara melengkapi jalan dengan pita penggaduh (rumble strips).

Kecepatan yang diizinkan pada areal jalan kampus Limau Manis UNAND berkisar antara 25 sampai dengan $30 \mathrm{~km} / \mathrm{jam}$. Berdasarkan observasi di lapangan ternyata pengendara kendaraan bermotor menjalankan kendaraannya melebihi kecepatan izin, walaupun sudah terdapat tanda batas kecepatan. Salah satu alat yang digunakan untuk mereduksi kecepatan di kampus Limau Manis UNAND adalah pita penggaduh (rumble strips). Sehingga perlu diteliti kecepatan real kendaraan ketika melewati rumble strips dan besar perubahan kecepatan lalu lintas akibat rumble strips di kawasan kampus Limau Manis UNAND.

\section{MetodePenelitian}

Adapun diagram alir yang digunakan untuk studi parameter mikroskopik dan makroskopik arus lalu lintas pada pengaruh rumble strips terhadap perilaku pengemudi di kampus Limau Manis Universitas Andalas adalah Gambar 1. 


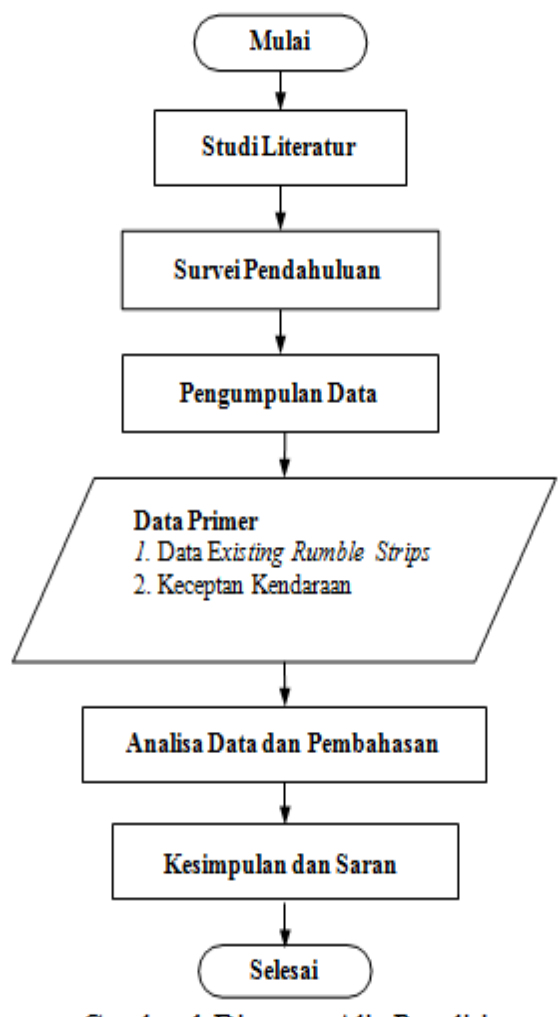

Gambar 1 Diagram Alir Penelitian

Survei Pendahuluan

Sebelum melakukan penelitian terlebih dahulu dilakukan studi pendahuluan antara lain:

a. Penentuan lokasi penelitian

Ada lima lokasi penempatan rumble strips di kampus Limau Manis UNAND pada Tabel 1.

Tabel 1. Lokasi Penempatan Rumble Strips di Kampus Limau Manis Unand

\begin{tabular}{|c|c|c|c|}
\hline \multirow{2}{*}{ NO } & \multirow{2}{*}{ Lokasi Rumble Strips } & \multicolumn{2}{|c|}{ Arah } \\
\cline { 3 - 4 } & & Naik & Turun \\
\hline 1. & Di depan Kopma & FMIPA-FT & FT-FMIPA \\
\hline 2. & Di depan PKM & - & PKM \\
\hline 3. & Di depan Fakultas Ekonomi & PKM-Faterna & Faterna-PKM \\
\hline 4. & Di depan Gedung futsal & Faperta- & Kopma- \\
\hline 5. & Di depan Fakultas & FE-Faperta & Faperta-FE \\
\hline
\end{tabular}


b. Penentuan titik pengukuran, dapat dilihat pada Gambar 2 berikut:

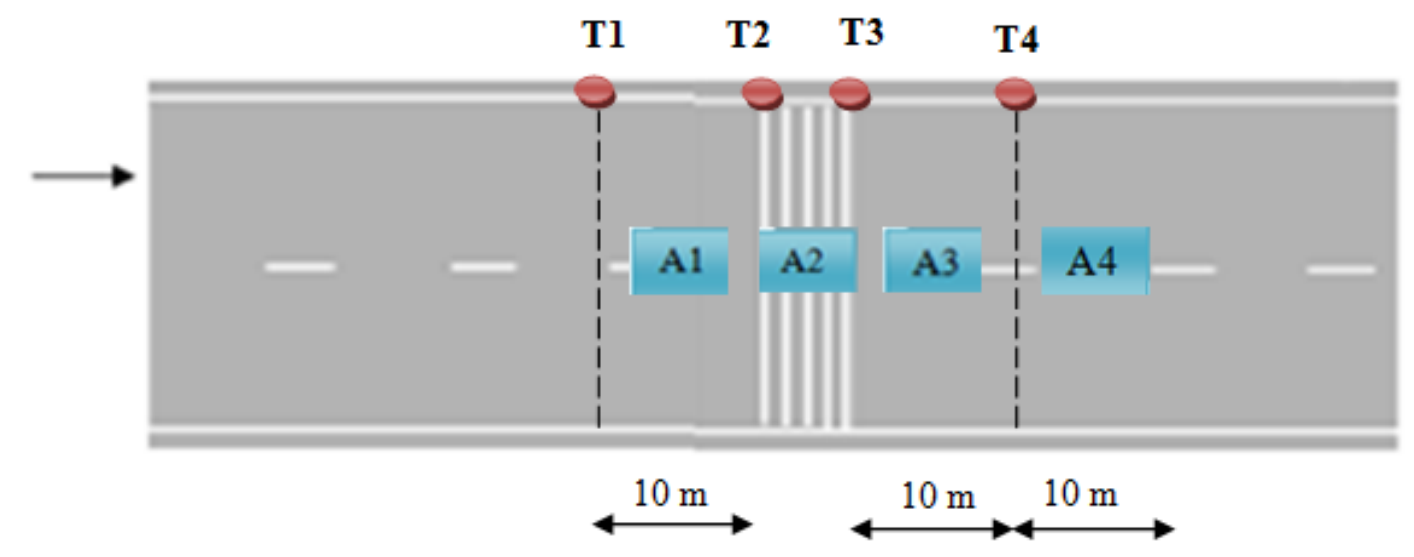

Keterangan titik survai :

: Area sebelum lokasi rumble strips

: Area saat menngilas rumble strips

: Area saat akan meninggalkan rumble strips

: Area setelah meninggalkan rumble strips

Gambar 2. Sketsa titik lokasi survei

c. Penentuan waktu survai

Survei dilakukan di semester pendek tanggal 14 Juni 2013- 4 juli 2013 pada hari kerja (jam08.45 WIB sampai jam 17.30 WIB).

Pengumpulan Data

Pengumpulan data primer dilakukan dengan cara survai di lapangan. Data primer dalam penelitian ini antara lain:

a. Data eksisting rumble strips

b. Data kecepatan Kendaraan 


\section{HasildanPembahasan}

\section{Hasil Pengolahan Data Survei}

\section{Survei kecepatan rata-rata kendaraan}

Hasil survei kecepatan rata-rata kendaraan ditunjukkan pada Gambar 3.

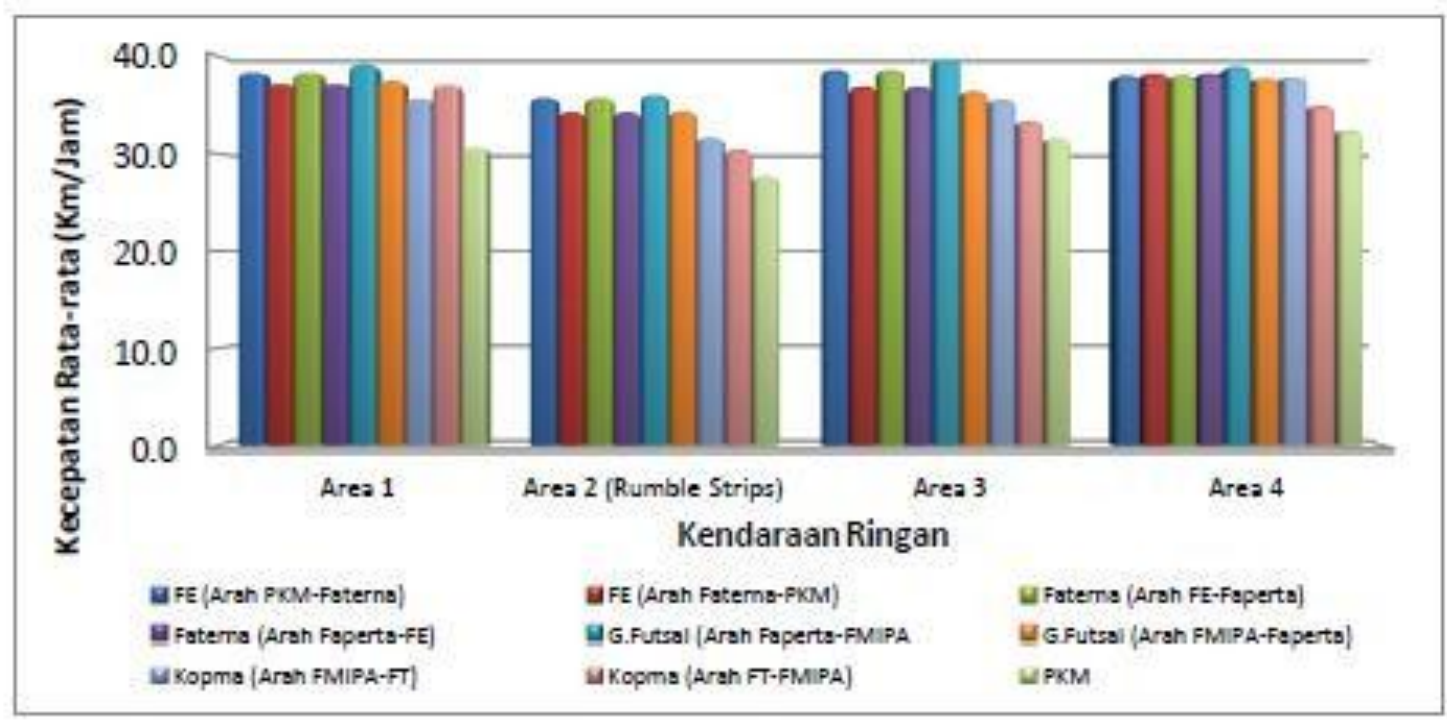

Gambar 3. Kecepatan Rata-rata Kendaraan Ringan

Pada setiap gambar harus diberikan keterangan di bawah gambar. Keterangan pada tabel diberikan di atas tabel. Keterangan dituliskan dengan huruf kecil kecuali pada karakter pertama pada tiap kalimat. Seluruh gambar harus diberi penomoran secara berurutan. Gambar diletakkan di tengah halaman (center alignment), sedangkan tabel diawali di pinggir kiri (left alignment) halaman. 


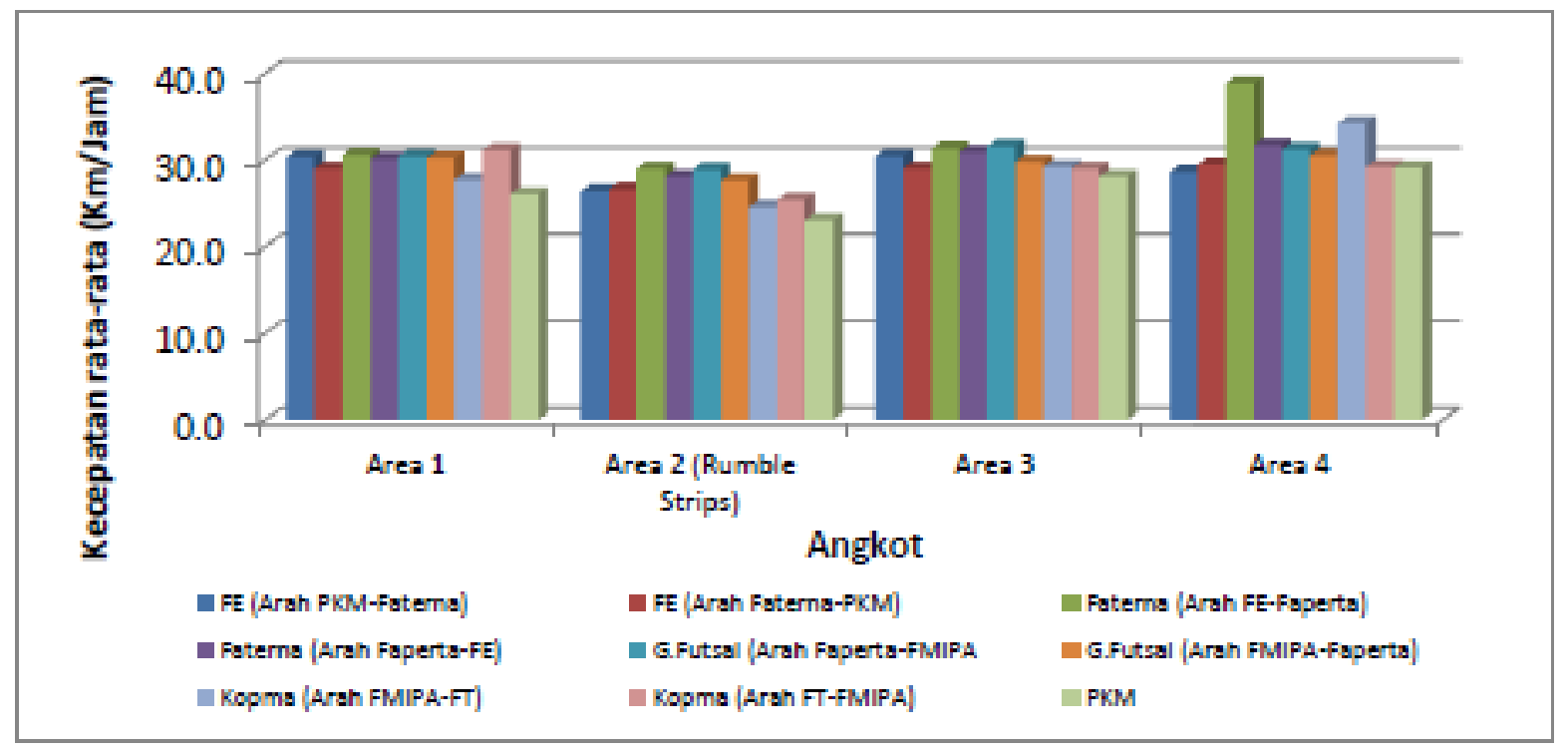

Gambar 4. Kecepatan Rata-rata Angkot

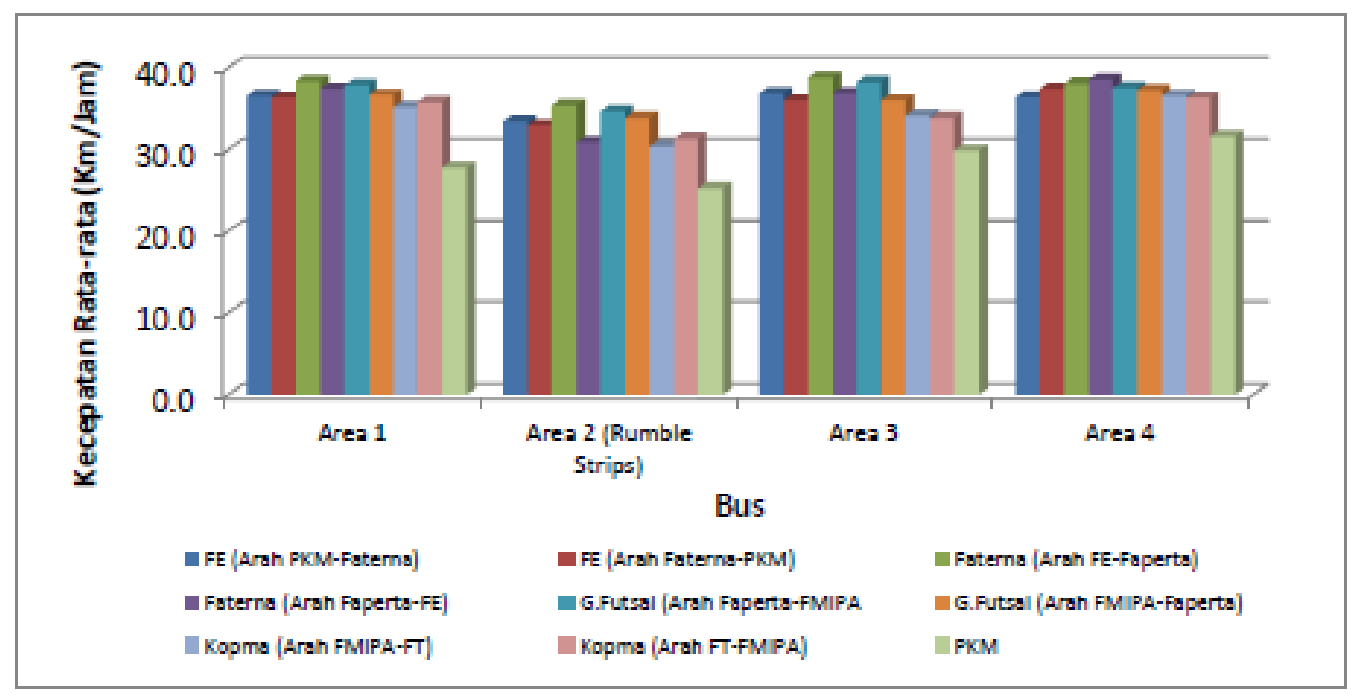

Gambar 4. Hasil Survei Kecepatan Rata-rata Bus

Dari gambar 4.dapat disimpulkan bahwa kecepatan rata-rata kendaraan di lokasi penelitian rumble strips mengalami penurunan kecepatan rata-rata di area 2 (Rumble Strips) di bandingkan dengan kecepatan rata-rata kendaraan di area 1 , area 3 dan area 4 . Ini disebabkan karena adanya pengaruh rumble strips terhadap penurunan kecepatan rata-rata sepeda motor yang melewati lokasi- lokasi tersebut 
Hasil Analisis Statistik

Hasil Analisis statistik dapat dilihat pada Tabel 2, 3, 4, 5, 6 berikut ini:

Tabel 2. Hasil Uji Hipotesis dan Chi Square Perubahan Kecepatan di depan FE

\begin{tabular}{|c|c|c|c|c|c|}
\hline \multirow[b]{2}{*}{$\begin{array}{c}\text { Jenis } \\
\text { Kendaraan }\end{array}$} & \multirow[b]{2}{*}{ Lokasi } & \multicolumn{2}{|c|}{ Arah PKM-Faterna } & \multicolumn{2}{|c|}{ Arah Faterna-PKM } \\
\hline & & $\begin{array}{l}\text { Keputusan } \\
\text { Uji z dan t }\end{array}$ & $\begin{array}{l}\text { Keputusan } \\
\text { Uji chi- } \\
\text { square }\end{array}$ & $\begin{array}{l}\text { Keputusan } \\
\text { Uji z dan t }\end{array}$ & $\begin{array}{l}\text { Keputusan } \\
\text { Uji chi- } \\
\text { square }\end{array}$ \\
\hline \multirow{3}{*}{$\begin{array}{l}\text { Sepeda } \\
\text { Motor }\end{array}$} & $\begin{array}{l}\text { Area 1-Area } 2 \\
\text { (Rumble strips) }\end{array}$ & ditolak & ditolak & ditolak & ditolak \\
\hline & $\begin{array}{l}\text { Area } 2 \text { (Rumble strips)- } \\
\text { Area } 3\end{array}$ & ditolak & ditolak & ditolak & ditolak \\
\hline & Area 3- Area 4 & ditolak & ditolak & ditolak & ditolak \\
\hline \multirow{3}{*}{$\begin{array}{l}\text { Kendaraan } \\
\text { Ringan }\end{array}$} & $\begin{array}{l}\text { Area 1-Area } 2 \\
\text { (Rumble strips) }\end{array}$ & ditolak & ditolak & ditolak & ditolak \\
\hline & $\begin{array}{l}\text { Area } 2 \text { (Rumble strips)- } \\
\text { Area } 3\end{array}$ & ditolak & ditolak & ditolak & ditolak \\
\hline & Area 3- Area 4 & ditolak & ditolak & ditolak & diterima \\
\hline \multirow{3}{*}{$\begin{array}{l}\text { Angkutan } \\
\text { Umum }\end{array}$} & $\begin{array}{l}\text { Area 1-Area } 2 \\
\text { (Rumble strips) }\end{array}$ & ditolak & ditolak & ditolak & ditolak \\
\hline & $\begin{array}{l}\text { Area 2(Rumble strips)- } \\
\text { Area } 3\end{array}$ & ditolak & ditolak & ditolak & ditolak \\
\hline & Area 3- Area 4 & ditolak & ditolak & diterima & diterima \\
\hline \multirow{3}{*}{ Bus } & $\begin{array}{l}\text { Area 1-Area } 2 \\
\text { (Rumble strips) }\end{array}$ & ditolak & ditolak & ditolak & ditolak \\
\hline & $\begin{array}{l}\text { Area 2(Rumble strips)- } \\
\text { Area } 3\end{array}$ & diterima & ditolak & ditolak & ditolak \\
\hline & Area 3- Area 4 & diterima & diterima & ditolak & diterima \\
\hline
\end{tabular}

Tabel 3. Hasil Uji Hipotesis dan Chi Square Perubahan Kecepatandi depan Faterna

\begin{tabular}{|c|c|c|c|c|c|}
\hline \multirow[b]{2}{*}{$\begin{array}{l}\text { Jenis } \\
\text { Kendaraan }\end{array}$} & \multirow[b]{2}{*}{ Lokasi } & \multicolumn{2}{|c|}{ Arah FE-Faperta } & \multicolumn{2}{|c|}{ Arah Faperta-FE } \\
\hline & & $\begin{array}{l}\text { Keputusan } \\
\text { Uji z dan t }\end{array}$ & $\begin{array}{l}\text { Keputusan } \\
\text { Uji chi- } \\
\text { square }\end{array}$ & $\begin{array}{l}\text { Keputusan } \\
\text { Uji z dan t }\end{array}$ & $\begin{array}{l}\text { Keputusan } \\
\text { Uji chi- } \\
\text { square }\end{array}$ \\
\hline \multirow{3}{*}{$\begin{array}{l}\text { Sepeda } \\
\text { Motor }\end{array}$} & $\begin{array}{l}\text { Area 1-Area2 } \\
\text { (Rumble strips) }\end{array}$ & ditolak & ditolak & ditolak & ditolak \\
\hline & $\begin{array}{l}\text { Area2(Rumblestrips)- } \\
\text { Area } 3\end{array}$ & ditolak & ditolak & ditolak & ditolak \\
\hline & Area 3- Area 4 & ditolak & diterima & ditolak & ditolak \\
\hline \multirow{3}{*}{$\begin{array}{l}\text { Kendaraan } \\
\text { Ringan }\end{array}$} & $\begin{array}{l}\text { Area 1-Area2 } \\
\text { (Rumble strips) }\end{array}$ & ditolak & ditolak & ditolak & ditolak \\
\hline & $\begin{array}{l}\text { Area2(Rumblestrips)- } \\
\text { Area } 3\end{array}$ & ditolak & ditolak & ditolak & ditolak \\
\hline & Area 3- Area 4 & diterima & diterima & ditolak & diterima \\
\hline \multirow{2}{*}{$\begin{array}{l}\text { Angkutan } \\
\text { Umum }\end{array}$} & $\begin{array}{l}\text { Area 1-Area2 } \\
\text { (Rumble strips) }\end{array}$ & ditolak & ditolak & ditolak & ditolak \\
\hline & Area2(Rumblestrips)- & ditolak & ditolak & ditolak & ditolak \\
\hline
\end{tabular}




\begin{tabular}{|c|c|c|c|c|c|}
\hline \multirow{4}{*}{$\begin{array}{c}\text { Jenis } \\
\text { Kendaraan }\end{array}$} & \multirow[b]{2}{*}{ Lokasi } & \multicolumn{2}{|c|}{ Arah FE-Faperta } & \multicolumn{2}{|c|}{ Arah Faperta-FE } \\
\hline & & $\begin{array}{l}\text { Keputusan } \\
\text { Uji z dan t }\end{array}$ & $\begin{array}{c}\text { Keputusan } \\
\text { Uji chi- } \\
\text { square }\end{array}$ & $\begin{array}{l}\text { Keputusan } \\
\text { Uji z dan t }\end{array}$ & $\begin{array}{c}\text { Keputusan } \\
\text { Uji chi- } \\
\text { square }\end{array}$ \\
\hline & Area 3 & & & & \\
\hline & Area 3- Area 4 & diterima & diterima & diterima & ditolak \\
\hline \multirow{3}{*}{ Bus } & $\begin{array}{l}\text { Area 1-Area2 } \\
\text { (Rumble strips) }\end{array}$ & ditolak & ditolak & ditolak & ditolak \\
\hline & $\begin{array}{l}\text { Area2(Rumblestrips)- } \\
\text { Area } 3\end{array}$ & ditolak & ditolak & diterima & diterima \\
\hline & Area 3-Area 4 & diterima & diterima & diterima & diterima \\
\hline
\end{tabular}

Tabel 4. Hasil Uji Hipotesis dan Chi Square Perubahan Kecepatan di depan Gedung Futsal

\begin{tabular}{|c|c|c|c|c|c|}
\hline \multirow[b]{2}{*}{$\begin{array}{l}\text { Jenis } \\
\text { Kendaraan }\end{array}$} & \multirow[b]{2}{*}{ Lokasi } & \multicolumn{2}{|c|}{ Arah Faperta- FMIPA } & \multicolumn{2}{|c|}{ Arah FMIPA-Faperta } \\
\hline & & $\begin{array}{l}\text { Keputusan } \\
\text { Uji z dan t }\end{array}$ & $\begin{array}{c}\text { Keputusan } \\
\text { Uji chi- } \\
\text { square }\end{array}$ & $\begin{array}{l}\text { Keputusan } \\
\text { Uji z dan t }\end{array}$ & $\begin{array}{c}\text { Keputusan } \\
\text { Uji chi- } \\
\text { square }\end{array}$ \\
\hline \multirow{3}{*}{$\begin{array}{l}\text { Sepeda } \\
\text { Motor }\end{array}$} & $\begin{array}{l}\text { Area 1-Area 2(Rumble } \\
\text { strips) }\end{array}$ & ditolak & ditolak & ditolak & ditolak \\
\hline & $\begin{array}{l}\text { Area } 2 \text { (Rumble strips)- } \\
\text { Area } 3\end{array}$ & ditolak & ditolak & ditolak & ditolak \\
\hline & Area 3-Area 4 & ditolak & ditolak & ditolak & ditolak \\
\hline \multirow{3}{*}{$\begin{array}{l}\text { Kendaraan } \\
\text { Ringan }\end{array}$} & $\begin{array}{l}\text { Area 1-Area 2(Rumble } \\
\text { strips) }\end{array}$ & ditolak & ditolak & ditolak & ditolak \\
\hline & $\begin{array}{l}\text { Area } 2 \text { (Rumble strips)- } \\
\text { Area } 3\end{array}$ & ditolak & ditolak & ditolak & ditolak \\
\hline & Area 3- Area 4 & diterima & diterima & ditolak & ditolak \\
\hline \multirow{3}{*}{$\begin{array}{l}\text { Angkutan } \\
\text { Umum }\end{array}$} & $\begin{array}{l}\text { Area 1-Area 2(Rumble } \\
\text { strips) }\end{array}$ & ditolak & ditolak & ditolak & ditolak \\
\hline & $\begin{array}{l}\text { Area } 2 \text { (Rumble strips)- } \\
\text { Area } 3\end{array}$ & ditolak & ditolak & ditolak & ditolak \\
\hline & Area 3-Area 4 & ditolak & diterima & ditolak & diterima \\
\hline \multirow{3}{*}{ Bus } & $\begin{array}{l}\text { Area 1-Area 2(Rumble } \\
\text { strips) }\end{array}$ & ditolak & ditolak & ditolak & ditolak \\
\hline & $\begin{array}{l}\text { Area } 2 \text { (Rumble strips)- } \\
\text { Area } 3\end{array}$ & ditolak & ditolak & ditolak & ditolak \\
\hline & Area 3- Area 4 & diterima & diterima & ditolak & diterima \\
\hline
\end{tabular}

Tabel 5. Hasil Uji Hipotesis dan Chi Square Perubahan Kecepatan di depan Kopma

\begin{tabular}{|c|c|c|c|c|c|}
\hline \multirow[b]{2}{*}{$\begin{array}{c}\text { Jenis } \\
\text { Kendaraan }\end{array}$} & \multirow[b]{2}{*}{ Lokasi } & \multicolumn{2}{|c|}{ Arah Faperta- FMIPA } & \multicolumn{2}{|c|}{ Arah FMIPA-Faperta } \\
\hline & & $\begin{array}{l}\text { Keputusan } \\
\text { Uji z dan t }\end{array}$ & $\begin{array}{c}\text { Keputusan } \\
\text { Uji chi- } \\
\text { square }\end{array}$ & $\begin{array}{l}\text { Keputusan } \\
\text { Uji z dan t }\end{array}$ & $\begin{array}{l}\text { Keputusan } \\
\text { Uji chi- } \\
\text { square }\end{array}$ \\
\hline \multirow{2}{*}{$\begin{array}{l}\text { Sepeda } \\
\text { Motor }\end{array}$} & $\begin{array}{l}\text { Area 1-Area 2(Rumble } \\
\text { strips) }\end{array}$ & ditolak & ditolak & ditolak & ditolak \\
\hline & $\begin{array}{l}\text { Area 2(Rumble strips)- } \\
\text { Area } 3\end{array}$ & ditolak & ditolak & ditolak & ditolak \\
\hline
\end{tabular}




\begin{tabular}{|c|c|c|c|c|c|}
\hline \multirow{3}{*}{$\begin{array}{c}\text { Jenis } \\
\text { Kendaraan }\end{array}$} & \multirow[b]{2}{*}{ Lokasi } & \multicolumn{2}{|c|}{ Arah Faperta- FMIPA } & \multicolumn{2}{|c|}{ Arah FMIPA-Faperta } \\
\hline & & $\begin{array}{l}\text { Keputusan } \\
\text { Uji z dan t }\end{array}$ & $\begin{array}{l}\text { Keputusan } \\
\text { Uji chi- } \\
\text { square }\end{array}$ & $\begin{array}{l}\text { Keputusan } \\
\text { Uji z dan t }\end{array}$ & $\begin{array}{l}\text { Keputusan } \\
\text { Uji chi- } \\
\text { square }\end{array}$ \\
\hline & Area 3- Area 4 & ditolak & ditolak & ditolak & ditolak \\
\hline \multirow{3}{*}{$\begin{array}{l}\text { Kendaraan } \\
\text { Ringan }\end{array}$} & $\begin{array}{l}\text { Area 1-Area 2(Rumble } \\
\text { strips) }\end{array}$ & ditolak & ditolak & ditolak & ditolak \\
\hline & $\begin{array}{l}\text { Area } 2 \text { (Rumble strips)- } \\
\text { Area } 3\end{array}$ & ditolak & ditolak & ditolak & ditolak \\
\hline & Area 3- Area 4 & ditolak & ditolak & ditolak & ditolak \\
\hline \multirow{3}{*}{$\begin{array}{l}\text { Angkutan } \\
\text { Umum }\end{array}$} & $\begin{array}{l}\text { Area 1-Area 2(Rumble } \\
\text { strips) }\end{array}$ & ditolak & ditolak & ditolak & ditolak \\
\hline & $\begin{array}{l}\text { Area } 2 \text { (Rumble strips)- } \\
\text { Area } 3\end{array}$ & ditolak & ditolak & ditolak & ditolak \\
\hline & Area 3- Area 4 & ditolak & ditolak & diterima & diterima \\
\hline \multirow{3}{*}{ Bus } & $\begin{array}{l}\text { Area 1-Area 2(Rumble } \\
\text { strips) }\end{array}$ & ditolak & ditolak & ditolak & ditolak \\
\hline & $\begin{array}{l}\text { Area } 2 \text { (Rumble strips)- } \\
\text { Area } 3\end{array}$ & ditolak & ditolak & ditolak & ditolak \\
\hline & Area 3- Area 4 & ditolak & ditolak & diterima & diterima \\
\hline
\end{tabular}

Tabel 6. Hasil Uji Hipotesis dan Chi Square Perubahan Kecepatan di depan Kopma

\begin{tabular}{|c|l|c|c|}
\hline \multirow{2}{*}{$\begin{array}{c}\text { Jenis } \\
\text { Kendaraan }\end{array}$} & \multicolumn{1}{|c|}{ Lokasi } & $\begin{array}{c}\text { Keputusan Uji z } \\
\text { dan t }\end{array}$ & $\begin{array}{c}\text { Keputusan Uji } \\
\text { chi-square }\end{array}$ \\
\hline \multirow{3}{*}{$\begin{array}{c}\text { Sepeda Motor } \\
\begin{array}{c}\text { Kendaraan } \\
\text { Ringan }\end{array}\end{array}$} & Area 1-Area 2 (Rumble Strips) & ditolak & ditolak \\
\cline { 2 - 4 } & Area 2(Rumble Strips)-Area 3 & ditolak & ditolak \\
\cline { 2 - 4 } & Area 3-Area 4 & ditolak & ditolak \\
\cline { 2 - 4 } & Area 1-Area 2 (Rumble Strips) & ditolak & ditolak \\
\cline { 2 - 4 } $\begin{array}{c}\text { Angkutan } \\
\text { Umum }\end{array}$ & Area 3-Area 4 & ditolak & ditolak \\
\cline { 2 - 4 } & Area 1-Area 2 (Rumble Strips) & ditolak & ditolak \\
\cline { 2 - 4 } & Area 3-Area 4 & ditolak & ditolak \\
\hline \multirow{2}{*}{\begin{tabular}{c} 
Bus \\
\cline { 2 - 4 }
\end{tabular}} & Area 1-Area 2 (Rumble Strips) & ditolak & ditolak \\
\cline { 2 - 4 } & Area 2(Rumble Strips)-Area 3 & ditolak & ditolak \\
\cline { 2 - 4 } & Area 3-Area 4 & ditolak & diterima \\
\hline
\end{tabular}

Berdasarkan perbandingan keputusan hasil uji z dan t dengan uji chi square, bahwa uji chi square hasil pengujiannya lebih detail, karena uji chi square menggunakan data distribusi frekuensi kecepatan masing-masing kendaraan, sedangkan uji z dan t menggunakan ratarata kecepatan masing-masing kendaraan. 


\section{Kesimpulan}

Berdasarkan hasil penelitian dan analisa yang dilakukan dapat diambil kesimpulan sebagai berikut:

a. Kecepatan rata-rata kendaraan di kawasan kampus UNAND Limau Manis sebelum rumble strips (area1) adalah 34,5 Km/jam, kecepatan rata-rata kendaraan ketika melewati rumble strips (area 2) adalah 31,2 km/Jam, kecepatan rata-rata kendaraan ketika akan meninggalkan rumble strips (area 3) adalah 34,5 Km/jam, sedangkan kecepatan rata-rata kendaraan ketika meninggalkan rumble strips adalah $35,3 \mathrm{~km} / \mathrm{jam}$.

b. Kecepatan rata-rata kendaraan di kawasan kampus UNAND Limau Manis mengalami penurunan sebanyak 10,6\% ketika melewati rumble strips (area 2) dibandingkan kecepatan rata-rata kendaraan sebelum melewati rumble strips (area 1), rata-rata kendaraan di area ketika akan meninggalkan rumble strips (area 3) naik 9,4\% dibanding ketika melewati rumble strips dan ketika melewati (area 4) setelah meninggalkan rumble strips, kecepatan rata-rata naik $2,4 \%$ dibanding ketika akan meninggalkan rumble strips (area 3).

c. Berdasarkan pengamatan dari 5 lokasi penelitian rumble strips, lokasi dibagi menjadi 3 segmen yang berbeda yaitu :

1) Lokasi penelitiaan rumble strips didepan FE, didepan Faterna dan di depan Gedung futsal dianggap mempunyai karakteristik yang hampir sama karena lokasi yang saling berdekatan, selain itu persamaan karakteristik ini bisa dilihat dari hasil uji z dan $t$ serta uji chi square menunjukan bahwa perubahan kecepatan tidak dipengaruhi oleh rumble strips ketika melewati area 3 menuju area 4 khususnya untuk kendaraan angkot dan bus, selain itu nilai rata-rata serta persentase penurunan kecepatan kendaraan ketika melewati rumble strips yang tidak jauh berbeda ketika melewati 3 lokasi tersebut.

2) Lokasi penelitian rumble strips di depan Kopma dianggap sedikit berbeda lokasi penelitian di depan FE, di depan Faterna dan di depan Gedung Futsal,Hasil uji z dan t seta uji chi square khususnya arah FMIPA-FT yg menunjukkan hasil perubahan kecepatan kendaraan disetiap area dipengaruhi oleh rumble strips, sedangkan untuk arah FT-FMIPA di area 3 menuju area 4 khususnya untuk kendaraan angkot dan bus,perubahan kecepatan tidak dipengaruhi oleh adanya rumble strips.

3) Lokasi di depan PKM dianggap cukup berbeda dengan 4 lokasi penelitian rumble strips sebelumnya karena rumble strips ditempatkan hanya pada arah turun saja kemudian dilokasi penelitian ini juga terdapat beberapa garis penggaduh sebelum rumble strips dan ini sangat berpengaruh terhadap hasil uji z dan t yg menunjukkan semua perubahan kecepatan kendaraan dipengaruhi rumble strips, sedangkan berdasarkan chi square khususnya untuk bus ketika melewati area 3 menuju area 4 perubahan kecepatan tidak di pengaruhi oleh rumble strips. Untuk rata-rata kecepatan kendaraan yang jauh lebih rendah dibandingkan 4 lokasi penelitian sebelumnya dan persentase penurunan kecepatan kendaraan ketika melewati rumble strip, selain itu lokasi penelitian di depan kopma ini adalah satu-satunya akses keluar menuju gerbang kampus, sehingga pada keadaan tertentu sering terjadi penumpukan kendaraan di lokasi penelitian ini dan menyebabkan kerapatan kendaraan yang cukup tinggi dibanding 4 lokasi lain dan time headway kendaraan yg rendah 


\section{Daftar Pustaka}

Anonim, 2013. Voice of America Organisai Kesehatan Dunia-WHO, diakses tanggal 10 april 2013,m.voaindonesia.com/a/1632186.html

Departemen Perhubungan. 1994, Keputusan Menteri Perhubungan Nomor 3 Tahun 1994 Tentang Alat Pengendali dan Pengaman Pemakai Jalan, Jakarta.

Julianto, E, N. 2010, Hubungan antara Kecepatan, Volume dan Kepadatan Lalu lintas Ruas Jalan Siliwangi Semarang, Jurnal Teknik Sipil \& Perencanaan, No 2 Volume 12-juli 2010, diakses tanggal 13 April 2013, journal.unnes.ac.id/nju/index.php/jtsp/.../1453

Michael J. C, Jame W. S and Jenny L. G. 1993, Rumble Strips and Pedestrian Savety, ITE Journal. Tamin O. Z. 2008.Perencanaan Pemodelan dan Rekayasa Transportasi, Penerbit ITB, Bandung.

Widya Graha Asana. 2007. Penyusunan Sistem Manajemen dan Pedoman Keselamatan Jalan dalam Kegiatan Pembangunan Jalan. Departemen Pekerjaan Umum

Sudjana.1992, Metoda Statistik, Edisi ke-5, Penerbit Tarsito, Bandung. 